\title{
Doing Educational Research - Overcoming Challenges into Practice. Book review
}

Ekkehard NUISSL・

Ed. by

\section{H. Hoveid, L. Ciolan, A. Paseka, S. M. da Silva Sage Publications, 2019, 335 pages}

This is an untypical book on educational research, for several reasons. One of these reasons is mentioned in the subtitle: "Overcoming challenges in practice". The idea of this publication is to present concrete cases with different research approaches and to discuss there the problems occurring in practice, giving at the same time recommendations how to solve them. In this sense there are presented different research methods in the educational field, f. e. literature reviews, storytelling, Data analysis and multi-level statistical modelling, longitudinal research.

A second reason to qualify this publication as an extraordinary contribution to pedagogical research publications is the integration of international and

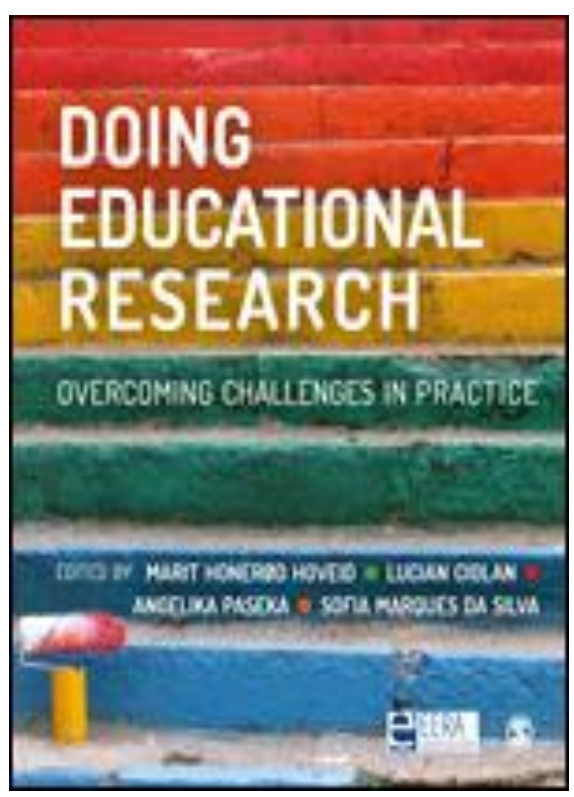
comparative aspects, due to the origin as a project publication, but covered by 4 international editors and 37 international contributors, working at different universities in different European countries. Like this there is a broad overview on topics in European contexts.

A third one is the fact that the publication is embedded in European organisational networks, EERA, the European Educational Research Association, is involved in this book. In EERA takes place a lot of the discussions on methods in educational research, mainly in the annual ECER - European Conference on Educational Research, the largest event of this kind of researchers in this field in Europe. The book was launched at the ECER in Hamburg, in September 2019. EERA is the most prestigious association of educational research in Europe, so such logo on a book talks by itself about a high-quality book, a must for an educational researcher. It is the first product of this kind with the EERA logo.

And a fourth one is the fact that the chapters in this book are readable, useful for beginners as well as experienced researchers. This is based on the perspective of the text, which shows not only methods and the way to apply them, but also the wider frame of the "fluid research field" of education.

\footnotetext{
• Prof.Dr.habil.Dr.h.c., Technischen Universität Kaiserslautern, e-mai: nuissl@die-bonn.de
} 
The presented methods are a selection, prioritizing the more complex approaches and the more modern ones, focussed on the special needs of the field. The contributions are some more, some less - critical, all of them trying to show a holistic view. Especially the descriptions of the process of research, the questions to answer in this process, the overcoming of obstacles are very helpful for other researchers, mainly since they are frankly described.

This book deserves a wider dissemination in the field, in the educational discussion all over Europe. 